\title{
HistóRia AMBiENTAL DE COMUNIDADES MOCAMBEIRAS NA AMAZÔNIA DURANTE A ESCRAVIDÃO E O PÓS-ABOLIÇÃO
}

DE LA TORRE, Oscar. The People of the River: Nature and Identity in Black Amazonia, 1835-1945. Chapel Hill: University of North Carolina Press, 2018. 238 p.

$\mathbf{E}_{\mathrm{m} \text { 2020, The People of the River }}$ ganhou o prêmio de melhor livro do GT Amazônia da LASA (Latin American Studies Association). Publicação baseada na tese de doutorado em História do autor, este livro já havia obtido, em 2019, um prêmio (Outstanding First Book Prize) da ASWAD -Association for the Study of the Worldwide African Diaspora. Sem dúvida, a obra é instigante e fascinante, com uma narrativa fluente, às vezes com doses de ironia bem aplicadas ao longo do texto.

Mas não se trata apenas de uma obra bem escrita, atributo importante em qualquer texto de história, como já dizia Marc Bloch. ${ }^{1}$ Para além de uma narrativa bem construída, a obra traz uma sólida pesquisa documental e bibliográfica a sustentá-la. O autor realizou trabalho de pesquisa em várias cidades paraenses (Alenquer, Belém, Óbidos, Santarém, Vigia), coletando fontes manuscritas e impressas, de natureza paroquial ou cartorial, entre outras, nos acervos de várias instituições. Também fez entrevistas com algumas dezenas de pessoas entre março e agosto de 2009, nas cidades de Alenquer,

1 Ver, por exemplo, as resenhas escritas por Marc Bloch, A terra e seus homens. Agricultura e vida rural nos séculos XVII e XVIII, Bauru: EDUSC, 2011. 
Santarém, Óbidos e Oriximiná, no Baixo Amazonas, e em Vigia, no nordeste paraense, além das pessoas entrevistadas nas comunidades quilombolas ou mocambeiras das ditas regiões. Nos Estados Unidos, na Sterling Memorial Library da Universidade de Yale consultou também a documentação do consulado norte-americano no Pará, entre 1831 e 1906. Os livros de diversos viajantes estrangeiros que percorreram a região amazônica ao longo do século XIX, muitos deles ainda não traduzidos, também foram fontes impressas importantes utilizadas pelo historiador.

Uma boa narrativa e uma sólida pesquisa que, no entanto, só teriam razão de ser pela escolha de um problema bem formulado de investigação historiográfica. A história das comunidades camponesas quilombolas e sua inserção na sociedade escravocrata e no pós-abolição adquirem novos contornos e significados a partir da perspectiva da história ambiental, amalgamada com a história econômica e política, nela inserindo os africanos e seus descentes, fossem escravizados ou, posteriormente, camponeses livres e/ou mocambeiros, numa Amazônia entendida enquanto processo de “crioulização ambiental”. Nas palavras do autor:

Com o conceito de crioulização ambiental, então, pretendo capturar as idéias, práticas, estratégias e discursos que escravos africanos e afro-brasileiros aprenderam não apenas ao se adaptarem ao Novo Mundo, mas também quando se tornaram camponeses livres (p. 7).

The People of the River segue de certa forma na trilha de alguns estudos sobre a escravidão nas Américas, que já consideravam a importância das paisagens naturais para compreender a adaptação e recriação de formas de viver dos africanos escravizados e seus descentes no Novo Mundo, sendo exemplo neste sentido os trabalhos da geógrafa Judith Carney sobre a introdução do arroz negro e a adoção das técnicas agrícolas de seu cultivo nas Américas, a partir do tráfico de escravos entre a região da Alta Guiné e o continente americano. ${ }^{2}$

2 Judith A. Carney, Arroz negro: as origens africanas do cultivo do arroz nas Américas, Bissau: Instituto da Biodiversidade e das Áreas Protegidas, 2018, p. 356; idem, “'With Grains in Her Hair': Rice, History and Memory in 
Porém, localizando o foco de sua análise na história ambiental, De la Torre buscou iluminar a compreensão da economia e da sociedade escravas na Amazônia fazendo uso do conceito de "crioulização ambiental" quando, por exemplo, tratou da configuração de uma economia paralela dos escravos em suas relações com a natureza (extrativismo), algo distinto da economia interna dos cativos por dentro do sistema escravista ("brecha camponesa”), uma vez que não seria uma economia restrita ao mundo rural das plantations. Afinal, me parece que faz sentido pensar numa economia paralela dos escravos, em alguma medida à revelia dos senhores, ainda que tolerada e, não menos verdade, parte também das relações escravistas mesmas, enquanto espaço de autonomia dos cativos, incorporando as paisagens naturais em suas vivências.

Poderia ser dito aqui que a ideia de “crioulização ambiental” se baseia no

Colonial Brazil”, Slavery and Abolition, v. 25, n. 1 (2004), pp. 1-27; idem e Richard Rosomoff, In the Shadow of Slavery: Africa's Botanical Legacy in the Atlântic World, Berkeley: University of California Press, 2009. processo de mestiçagem da população escrava e sua cultura na região amazônica, cada vez mais crioulas, no sentido de nascidas no Brasil, com a diminuição da taxa de africanidade dessa população e da liberta desde meados do século XIX, realidade demográfica já apontada por diversos estudos com os quais o autor, inclusive, dialoga no livro em pauta. ${ }^{3}$ Todavia, ainda que o conceito de mestiçagem, já pensado por vários desses estudos, implique numa compreensão cultural, para além da questão demográfica, penso que neste livro temos a mestiçagem (ou crioulização, para usarmos o termo escolhido pelo autor) com uma forte pegada da história ambiental. Há nisso uma contribuição importante e concordo, portanto, com o autor quando escreve que "o enfoque no processo de crioulização ambiental tem o potencial de gerar uma nova perspectiva sobre a história da escravidão (p. 8).

No primeiro, segundo e terceiro capítulos, bem como em parte do

3 Ver, por exemplo, Vicente Salles, $O$ negro no Pará sob o regime da escravidão, Brasília: Ministério da Educação; Belém: Fundação Cultural Tancredo Neves, 1988; e José Maia Bezerra Neto, Escravidão negra no Grão-Pará (sécs. XVII-XIX), Belém: Editora Paka-Tatu, 2011. 
quinto, o autor nos remete para o período da escravidão. Enfatizando seus aspectos sociais, econômicos e demográficos, ele aborda o trabalho nas fazendas e plantações nos sertões da Amazônia. Faz então uma bela narrativa das plantações de cacau, em sua maior parte o domesticado, principal commodity até meados do século XIX e a segunda mais importante até fins do século XIX e inicio do $\mathrm{XX}$, quando do crescimento do negócio da borracha.

Nas plantações de cacau, lá estavam os escravos de origem africana, bem como sujeitos livres ou libertos, na sua maioria índios ou não-brancos subordinados a alguma forma de trabalho forçado. Nessas propriedades, no entanto, não se cultivava apenas o cacau, mas também cana de açúcar, arroz, algodão, mandioca, café e outras plantas e árvores frutíferas, bem como se criava gado. Acrescentem-se os produtos da floresta, obtidos por meio da coleta, da caça ou da pesca. Portanto, extrativismo, policultura e uso de índios e escravos caracterizavam o mundo rural amazônico. Realidade da qual dá conta De la Torre, estando de acordo com o que tem apresentado a moderna historiografia sobre a região amazônica, com a qual dialoga. Mas ele não faz uso dos termos agroextrativismo e policultura em sua perspectiva da história ambiental.

Aqui vale uma observação: prefiro usar os termos fazenda e plantação, ao invés do termo plantation usado na obra, ainda que seja possível dizer que a caracterização do que seria a plantation amazônica, pelo autor do livro, não seja distinta da definição de fazenda ou plantação que penso mais apropriada para o mundo rural na região. Minha preferência se dá pelo fato de que o termo plantation, tal como usual na historiografia brasileira a partir da escrita em língua inglesa, ou seja, a grande unidade de produção agroexportadora, monocultora, assentada no trabalho escravo, não se adequaria à realidade amazônica.

Os quarto e sexto capítulos, e parte do quinto, abarcam o período pós-abolição, adentrando quase toda a primeira metade do século XX. No quarto e sexto capítulos acompanhamos as histórias dos mocambeiros do Baixo Amazonas e seus afluentes, mas agora inseridos na economia extrativista da castanha do Pará, como 
trabalhadores ou coletores no período posterior ao fim da escravidão. Sem exagero, a história da economia da castanha do Pará não será mais a mesma depois deste livro. Ainda que nos faltem mais pesquisas sobre as décadas de 1910 até a de 1940, no que tange ao conhecimento sobre a economia e a sociedade amazônicas, particularmente em seus interiores, parte dessa lacuna foi preenchida com o estudo de De la Torre.

No quinto capítulo, o autor trata dos “cidadãos de Tauapará”, lançando seu olhar sobre a comunidade de camponeses negros da região da Vigia, na Região do Salgado Paraense (ou Nordeste Paraense), próximo ao litoral Atlântico, distante portanto do Baixo Amazonas, no qual analisou as comunidades mocambeiras. Neste capítulo ele elegeu como objeto de sua investigação os camponeses negros descentes de escravos da fazenda Santo Antônio da Campina, próximo da cidade de Vigia, que lá viviam há algumas gerações, desde a época da escravidão, usufruindo então da terra e de seus bens naturais, embora não fossem proprietários documentados da propriedade. Eram então, ao longo do século $\mathrm{XX}$, mais do que "cidadãos de Tauapará”, sujeitos que foram se percebendo como cidadãos brasileiros, embora identificados enquanto comunidade quilombola do Cacau que, associando as paisagens naturais à sua história e identidade, buscava seu direito à terra e o seu reconhecimento perante a lei. Enfim, o estudo comparativo da comunidade do Cacau com as comunidades mocambeiras do Baixo Amazonas permitiu ao autor argumentar que as paisagens naturais foram importantes e indispensáveis "instrumentais tanto para a preservação quanto para a reconfiguração de uma identidade camponesa negra nas décadas após a emancipação” (p. 11).

Um esclarecimento, no entanto. Embora eu faça aqui essa divisão entre os capítulos, não foi essa a intenção do autor do livro, ou seja, compartimentá-los. Muito pelo contrário. Sua compreensão das comunidades camponesas negras mocambeiras perpassa o tempo da escravidão e da pós-abolição, percebendo suas diferenças contextuais, mas também aquilo que dá sentido a suas histórias.

Enfim, The People of the River trata da escravidão e do pós-emancipação na Amazônia brasileira, enfocando as conexões entre o meio ambiente, 
o trabalho e a identidade, a partir das histórias de trabalhadores escravizados e das comunidades camponesas mocambeiras, vindo ao encontro da recente historiografia brasileira, particularmente a amazonista. Por outro lado, lança novas luzes sobre essa historiografia, principalmente a partir da perspectiva da história ambiental. O livro é, no final das contas, uma contribuição importante para a historiografia da Amazônia e, portanto, do Brasil, especificamente para os estudos históricos acerca das comunidades quilombolas e mocambeiras nas Américas.

Enfim, encerrando esta resenha, ciente que deixo de comentar muitos outros aspectos interessantes, se me permitem um pouco de coloquialismo, gostaria apenas de dizer que curti muito a leitura desta obra.

\section{José Maia Bezerra Neto (DD}

Universidade Federal do Pará. 